\title{
PENGARUH WORK FAMILY CONFLICT DAN EMOTIONAL EXHAUSTION TERHADAP KINERJA PERAWAT WANITA MELALUI ORGANIZATIONAL COMMITMENT PADA RUMAH SAKIT PETROKIMIA GRESIK
}

\author{
Dewi Ayu Lestari \\ Universitas Negeri Surabaya \\ dewiayu011297@gmail.com \\ Budiono \\ Universitas Negeri Surabaya \\ ec.budiono@unesa.ac.id
}

\begin{abstract}
This research aims to analyze the impact of work-family conflict and emotional exhaustion on female nurse performance through organizational commitment in Petrokimia Gresik Hospital. This study is using quantitative methods. The population in this study is 46 respondents. Saturation sampling is the sampling technique used in this study and obtained 46 respondents. Structural Equation Modeling (SEM) with the help of software SmartPLS is the analysis technique used in this study. The study found that work-family conflict has a significant negative effect on job performance. Work-family conflict has a significant negative effect on organizational commitment. Emotional exhaustion has a significant negative effect on job performance. Emotional exhaustion has a significant negative effect on organizational commitment. Organizational commitment has a significant positive effect on job performance. Work-family conflict has a significant result in job performance through organizational commitment. Emotional exhaustion has a significant result in job performance through organizational commitment.
\end{abstract}

Keywords: emotional exhaustion; job performance; organizational commitment; work family conflict.

\section{PENDAHULUAN}

Sumber daya manusia berfungsi dalam penetapan sistem, rencana, proses dan tujuan perusahaan. Sumber daya manusia juga termasuk salah satu fungsi utama dari manajamen di suatu perusahaan di mana fungsi tersebut adalah untuk mendorong agar semua karyawan memiliki kinerja yang tinggi. Terlepas dari semua faktor dan kondisi yang ada di organisasi, kinerja karyawan juga dianggap menjadi hal penting bagi seluruh organisasi (Hasibuan dalam Septyaningsih \& Palupiningdyah 2017). Nabila et al. (2019) berpendapat bahwa karyawan ibarat seperti aset penting bagi sebuah perusahaan karena salah satu faktor penentu dalam kesuksesan yang diraih oleh organisasi adalah tingkat produktivitas dan kualitas tenaga kerja. Oleh sebab itu, kinerja karyawan sangat penting dan harus diperhatikan oleh perusahaan. Setiap perusahaan harus berupaya agar tidak terjadi penurunan kinerja pada karyawan yang akan dapat menghambat jalannya operasional perusahaan.

Penurunan kinerja karyawan salah satunya dapat disebabkan karena adanya work family conflict (Agustina \& Sudibya, 2018). Menurut Nabila et al. (2019), work family conflict seringkali muncul disebabkan dari pekerjaan yang mempunyai jam kerja tidak fleksibel, tingginya beban kerja, stres pada pekerjaan yang dirasakan, konflik diri dengan tim di tempat kerja, atau kurangnya dukungan dari kepala organisasi juga memiliki pengaruh terhadap realisasi tanggung jawabnya kepada keluarga. Kondisi seperti ini juga dapat mengusik pikiran ataupun mental seorang karyawan ketika bekerja. Penelitian terdahulu dari Septyaningsih \& Palupiningdyah (2017), Sudirno \& Nurvianti (2015), Zain \& Setiawati (2019), Agustina \& Sudibya (2018), Mubassyir \& Herachwati (2014), Nabila et. al. (2019), dan Setyawan (2019) mengindikasikan bahwa variabel work family conflict memiliki pengaruh signifikan negatif terhadap kinerja. Namun Maherani dalam Khulub \& Hidayati (2019) mengungkapkan bahwa peran ganda tidak memiliki pengaruh signifikan terhadap kinerja.

Faktor lainnya yang memicu turunnya kinerja karyawan yaitu kelelahan emosional (emotional exhaustion) (Sudirno \& Nurvianti, 2015). Agustina \& Sudibya (2018) mengungkapkan bahwa kinerja 
Dewi Ayu Lestari \& Budiono. Pengaruh Work Family Conflict dan Emotional Exhaution terhadap Kinerja Perawat Wanita melalui Organizational Commitment pada Rumah Sakit Petrokimia Gresik

seorang individu dapat menurun dikarenakan adanya sikap dan juga perilaku yang negatif. Stres yang berlebihan pada akhirnya akan menjadi penyebab timbulnya kelelahan emosional. Kelelahan emosional yang muncul dalam diri karyawan akan memiliki dampak terhadap kinerjanya terutama pada perasaan puas terhadap pekerjaan dan organizational commitment (Churiyah dalam Santika \& Sudibia, 2017). Septyaningsih \& Palupiningdyah (2017), Sudirno \& Nurvianti (2015), dan Tourigny et. al. (2013) mengungkapkan bahwa variabel emotional exhaustion memiliki pengaruh signifikan negatif terhadap kinerja karyawan.

Organizational commitment merupakan faktor lainnya yang bisa berpengaruh terhadap kinerja karyawan (Khan \& Zia-Ud-Din, 2013). Mitchel dalam Mubassyir \& Herachwati (2014) memandang organizational commotment sebagai suatu ukuran terhadap kinerja yang menjelaskan bahwa seorang karyawan sangat peduli dan mementingkan pekerjaannya. Karyawan tersebut akan merasa bahwa pekerjaannya saat ini telah memberikan kenyamanan, dan pekerjaan memberikan status bagi individu. Pendapat lain disampaikan oleh Meyer \& Allen's dalam Mubassyir \& Herachwati (2014). Organizational commitment adalah suatu keadaan yang memengaruhi psikologis, yakni karakteristik antara hubungan karyawan dengan organisasinya dan keterikatan karyawan dalam memutuskan untuk tetap ingin menjadi anggota dari organisasi. Penelitian yang dilakukan oleh Zain \& Setiawati (2019), Mubassyir \& Herachwati (2014), Tourigny et. al. (2013), Khan \& Zia-Ud-Din (2013), Suharto et. al. (2019), dan Memari et. al. (2013) menyatakan bahwa organizational commitment memiliki pengaruh positif dan signifikan terhadap kinerja karyawan. Namun pendapat lain disampaikan oleh Murty \& Hudiwinarsih (2012) dan Askolani \& Maulid (2019) bahwa organizational commitment tidak berpengaruh terhadap kinerja karyawan.

Work family conflict merupakan faktor lainnya yang dapat berpengaruh terhadap organizational commitment (Akintayo, 2010). Siwi dalam Mubassyir \& Herachwati (2014) mengatakan bahwa wanita yang memutuskan untuk bekerja lebih rentan merasakan adanya konflik peran. Dengan demikian, pengaruh besar atau kecilnya kemungkinan terjadinya work family conflict dapat mengacu pada perubahan komitmen organisasi pada karyawan wanita. Penelitian terdahulu yang dilakukan Akintayo (2010), Mubassyir \& Herachwati (2014), Khulub \& Hidayati (2019), dan Jenitta \& Elangkumaran (2013) mengindikasikan variabel work family conflict memiliki pengaruh signifikan negatif terhadap organizational commitment. Namun pendapat lain disampaikan oleh Zain \& Setiawati (2019) bahwa tidak terdapat pengaruh yang signifikan dari work family conflict terhadap organizational commitment.

Emotional exhaustion merupakan faktor lainnya yang dapat berpengaruh terhadap organizational commitment (Zhen, 2013). Emotional exhaustion adalah rasa lelah pada diri seseorang yang memiliki hubungan dengan emosional pribadi diawali dengan munculnya perasaan yang kurang semangat dan merasakan depresi (Caputo dalam Khulub \& Hidayati, 2019). Profesi dalam bidang pelayanan, ketika karyawan wanita yang bekerja dan mengalami tuntutan untuk mengatasi perbedaan karakteristik seseorang yang berbeda-beda adalah suatu pekerjaan yang sangat melibatkan emosional, dan tidak menutup kemungkinan pula terkadang harus mendapatkan suatu pengalaman kurang menyenangkan dengan pelanggan ataupun orang lain sehingga menyebabkan timbulnya ketegangan emosional (Khulub \& Hidayati, 2019). Penelitian terdahulu antara lain Herlina \& Rachmawati (2014), Khulub \& Hidayati (2019), Santika \& Sudibia (2017), Churiyah (2017), Ahmed (2015), Tourigny et. al. (2013), Rehman et. al. (2012), dan Zhen (2013) mengungkapkan bahwa emotional exhaustion memiliki pengaruh signifikan negatif terhadap organizational commitment.

Penelitian ini mengambil objek di Rumah Sakit Petrokimia Gresik (RSPG), di mana RSPG merupakan salah satu bidang usaha yang dimiliki PT. Petro Graha Medika (PGM) di mana PT. Petro Graha Medika (PGM) juga adalah anak perusahaan dari PT Petrokimia Gresik. Rumah Sakit Petrokimia Gresik dalam mewujudkan tujuan perusahaan agar dapat tercapai, maka sangat membutuhkan kinerja karyawan yang tinggi. Rumah sakit dituntut untuk memberikan layanan kesehatan bermutu tinggi dan dapat dijangkau oleh setiap elemen masyarakat untuk meningkatkan pelayanan kesehatan yang optimal bagi masyarakat. Sehubungan dengan hal itu, diperlukan perawat yang berkualitas dan professional (Agustina \& Sudibya, 2018). 
Perawat professional adalah perawat yang mampu memberikan perawatan berkualitas untuk memenuhi kebutuhan kesehatan pasien. Perawat professional bukan hanya berperan melaksanakan perawatan saja tetapi juga mampu berperan sebagai pendidik, komunikator dan manajer (Agustina \& Sudibya, 2018). Patrice dalam Agustina \& Sudibya (2018) menyatakan perawat wanita kesulitan membagi waktu untuk keluarga dan pekerjaan karena tanggung jawabnya sebagai perawat dan ibu rumah tangga, hal inilah yang dapat memicu terjadinya konflik pekerjaan dan keluarga.

Berdasarkan hasil pengamatan di Rumah Sakit Petrokimia Gresik, kondisi yang menjadi sumber perawat mengalami stres dan bahkan mengalami kelelahan emosional adalah keluarga pasien yang berisik sehingga mengganggu pasien lainnya dan mengganggu konsentrasi perawat dalam mengerjakan tugasnya. Perawat juga sering kali meminta ijin istirahat lebih awal karena urusan keluarga mereka, pada akhirnya perawat menggunakan waktu ijin melebihi dari yang diberikan oleh atasan sehingga jam kerja perawat berkurang dari jam yang sudah ditentukan. Hal ini akan memiliki dampak terhadap kinerja mereka yang tidak optimal salah satunya diindikasikan oleh jumlah pasien yang diperiksa kurang dari yang seharusnya.

Tujuan penelitian ini ialah untuk mengetahui apakah terdapat pengaruh antara work family conflict dan emotional exhaustion terhadap kinerja karyawan perawat wanita yang sudah menikah pada Rumah Sakit Petrokimia Gresik melalui organizational commitment.

\section{KAJIAN PUSTAKA DAN PENGEMBANGAN HIPOTESIS}

\section{Work Family Conflict}

Septyaningsih \& Palupiningdyah (2017) mengartikan bahwa work family conflict merupakan keadaan ketika seorang individu mempunyai dua peran yaitu sebagai bagian dalam keluarga dan sebagai karyawan dalam organisasi, namun karyawan tersebut memiliki kendala dalam pemenuhan tanggung jawab salah satu peran karena peran lainnya. Sebenarnya work family conflict dapat dirasakan oleh pria ataupun wanita, namun dalam banyaknya penelitian mengungkapkan bahwa seorang wanita memiliki lebih besar peluang mengalami work family conflict (Mubassyir \& Herachwati, 2014).

Work Family Conflict (WFC) yaitu keadaan di mana sebagian besar waktu dan perhatian dari karyawan Rumah Sakit Petrokimia Gresik difokuskan dalam melakukan pekerjaan sehingga karyawan akan merasa kurang memiliki waktu untuk keluarganya (Frone dalam Agustina \& Sudibya, 2018). Indikator Work Family Conflict (WFC) pada penelitian ini menggunakan indikator dari Netemeyer et. al. dalam Mubassyir \& Herachwati (2014) yaitu pekerjaan kantor mengintervensi kehidupan keluarga dan rumah tangga, tuntutan waktu dalam pekerjaan kantor membawa kesulitan dalam mengurus rumah, keluarga atau tanggung jawab pribadi, hal yang ingin dilakukan di rumah tidak dapat dilakukan karena tuntutan dari pekerjaan kantor, pekerjaan menimbulkan stres yang membawa kesulitan untuk memenuhi kewajiban aktivitas bersama keluarga, dan kurangnya dukungan dari keluarga.

\section{Emotional Exhaustion}

Kelelahan emosional (emotional exhaustion) yaitu kelelahan yang dirasakan pada diri seseorang yang memiliki hubungan dengan emosional pribadi dan diawali dengan adanya rasa kurang nyaman dan depresi (Churiyah, 2017). Karyawan yang mengalami emotional exhaustion, mereka akan merasa kurang bersemangat dan oleh sebab itu merasa enggan untuk melakukan sesuatu bagi organisasinya dan menurut mereka organisasi yang harus bertanggung jawab atas kelelahan emosional yang mereka rasakan (Santika \& Sudibia, 2017).

Emotional exhaustion adalah suatu kondisi di mana energi yang dialami dan dirasakan karyawan Rumah Sakit Petrokimia Gresik telah berkurang karena sumber dari emosinya telah dipergunakan untuk menghadapi adanya permintaan psikologis secara berlebihan (Septyaningsih \& Palupiningdyah, 2017). Indikator kelelahan emosional (emotional exhaustion) yang digunakan pada penelitian ini menggunakan indikator dari Khulub \& Hidayati (2019) yang terdiri dari beban kerja yang berlebihan 
Dewi Ayu Lestari \& Budiono. Pengaruh Work Family Conflict dan Emotional Exhaution terhadap Kinerja Perawat Wanita melalui Organizational Commitment pada Rumah Sakit Petrokimia Gresik

mengakibatkan rasa bosan, lelah atau merasakan ketidakpuasan dengan pekerjaan, merasa lelah pada saat akhir jam kerja, enggan melakukan pekerjaan, merasa frustasi atau tegang bila bekerja dengan orang lain, dan tidak peduli dengan rekan kerja.

\section{Organizational Commitment $(\mathbf{Z})$}

Askolani \& Maulid (2019) menyebutkan bahwa komitmen organisasi (organizational commitment) adalah salah satu sikap kerja, di mana karyawan akan merenungkan perasaanya terhadap organisasi tempat dia bekerja, dan ketika karyawan merasa nyaman dan menyukai organisasinya, ia akan berusaha untuk tetap bekerja di sana. Sedangkan Suharto et. al. (2019) menjelaskan bahwa komitmen organisasi mencakup kepercayaan diri yang tinggi dan karyawan dapat merasa sejalan dengan tujuan dan juga nilai-nilai yang ada pada organisasi dan bersedia dalam melakukan perubahan besar untuk organisasi.

Organizational Commitment (OC) adalah keadaan dari psikologis yang memiliki kharakteristik yaitu hubungan dari karyawan Rumah Sakit Petrokimia Gresik terhadap perusahaan atau sebuah dampak yang bisa memengaruhi apakah seorang karyawan Rumah Sakit Petrokimia Gresik akan memilih untuk bertahan dengan organisasi atau tidak dan perasaan percaya pada nilai-nilai organisasi (O'Reilly dalam Mubassyir \& Herachwati, 2014). Pada penelitian ini menggunakan indikator dari Meyer \& Allen's dalam Mubassyir \& Herachwati (2014) yaitu sebagai berikut. (1) Affective commitment ialah karyawan yang mempunyai komitmen afektif lebih kuat, ia akan berusaha untuk bertahan dengan perusahaan dan memiliki keinginan menjadi bagian dari perusahaan (want to). (2) Continuance commitment ialah komitmen yang mendasar pada kesadaran financial yang ada hubungannya dengan resiko apabila karyawan meninggalkan organisasi atau perusahaan. Karyawan yang memiliki komitmen berkelanjutan yang kuat akan tetap mempertimbangkan untuk berada di dalam organisasi dengan alasan mereka yang membutuhkannya (need to). (3) Normative commitment iala apabila komitmen normatif dalam diri karyawan tergolong tinggi, maka karyawan akan memutuskan untuk mengupayakan bagaimana caranya agar mereka tetap tinggal dengan perusahaan karena mereka merasa harus melakukan hal tersebut (ought to).

\section{Kinerja Karyawan}

Sudirno \& Nurvianti (2015) mengungkapkan kinerja merupakan hasil dari pekerjaan yang dicapai karyawan ketika melaksanakan tugas-tugas dan tanggungjawab yang telah diberikan kepada mereka melalui dasar atas kemampuan, pengalaman, kerja keras, dan waktu. Pada penelitian ini, variabel terikat yaitu kinerja yang merupakan pencapaian pekerjaan dari karyawan berdasarkan kriteria yang sudah ditetapkan oleh Rumah Sakit Petrokimia Gresik. Dalam penelitian ini indikator pengukur kinerja karyawan mengacu pada Gomes (dalam Setyawan, 2019), di antaranya ialah quantity of works, quality of works, job knowledge, creativeness, cooperative, dependability, initiative, dan personal qualities.

\section{Hubungan antar Variabel}

Work family conflict akan terjadi ketika terdapat bermacam-macam desakan yang datang dari banyak sumber dan dapat membuat karyawan menjadi sulit untuk memilih apa dan mana yang harus diwujudkan tanpa membuat beberapa desakan yang lainnya diabaikan (Mubassyir \& Herachwati, 2014). Terjadinya work family conflict dalam diri karyawan memiliki dampak negatif berupa: (1) peningkatan stres yang dirasakan karyawan, (2) peningkatan rasa ketidakpuasan, (3) menurunnya produktivitas kerja, dan (4) menurunnya kinerja (Sudirno \& Nurvianti, 2015). Agustina \& Sudibya (2018), Zain \& Setiawati (2019), Septyaningsih \& Palupiningdyah (2017), Nabila et. al. (2019), dan Setyawan (2019) mengungkapkan bahwa variabel work family conflict memiliki pengaruh negatif dan signifikan terhadap kinerja karyawan. Artinya, apabila meminimalkan dan mengantisipasi konflik pekerjaan keluarga dengan baik, maka akan terjadi peningkatan kinerja karyawan.

H1: Diduga work family conflict berpengaruh signifikan negatif terhadap kinerja karyawan.

Pengaruh dari work family conflict terhadap organizational commitment berdasarkan penelitian Khulub \& Hidayati (2019) menunjukkan variabel work family conflict memiliki pengaruh negatif dan 
signifikan terhadap organizational commitment. Hubungan negatif dari work family conflict terhadap organizational commitment dapat ditinjau dari adanya karyawan yang merasa kesulitan dalam menyetarakan perannya ketika di tengah-tengah keluarga ataupun di dunia pekerjaan sehingga menyebabkan karyawan akan merasa kurang memiliki komitmen terhadap organisasinya. Pendapat serupa juga diungkap dalam penelitian Jenitta \& Elangkumaran (2013), Mubassyir \& Herachwati (2014), Akintayo (2010), dan Sihaloho \& Handayani (2018) yang menunjukkan bahwa variabel work family conflict mempunyai pengaruh yang signifikan negatif terhadap organizational commitment, artinya ketika tingkat work family conflict berada pada posisi yang tinggi maka organizational commitment terhadap perusahaan akan menurun, dan bermakna sebaliknya.

H2: Diduga work family conflict berpengaruh signifikan negatif terhadap organizational commitment.

Santika \& Sudibia (2017) mengungkapkan tingkah laku negatif yang dialami akibat stres berlebih dapat menyebabkan emotional exhaustion dan memiliki dampak pada turunnya kinerja individu. Emotional exhaustion adalah respon dalam diri setiap orang terhadap stres yang dirasakan karena adanya dorongan dari emosional yang sangat tinggi, munculnya anggapan seolah tidak ada satupun yang dapat membantunya, putus asa, depresi, dan perasaan yang terbelenggu (Sudirno \& Nurvianti, 2015). Septyaningsih \& Palupiningdyah (2017), Sudirno \& Nurvianti (2015), dan Tourigny et. al. (2013) menjelaskan bahwa emotional exhaustion memiliki pengaruh positif terhadap kinerja karyawan. Semakin rendah karyawan merasakan emotional exhaustion pada dirinya maka dalam kinerjanya akan meningkat, dan bermakna sebaliknya.

H3: Diduga emotional exhaustion berpengaruh signifikan negatif terhadap kinerja karyawan.

Emotional exhaustion berpengaruh signifikan negatif terhadap organizational commitment, ketika emotional exhaustion yang dihadapi karyawan semakin tinggi, maka organizational commitment semakin rendah akibat emotional exhaustion yang dirasakannya, dan sebaliknya (Santika \& Sudibia, 2017). Pendapat tersebut sesuai dengan Tourigny et. al. (2013), Zhen (2013), Ahmed (2015), Herlina \& Rachmawati (2014), dan Khulub \& Hidayati (2019), bahwa variabel emotional exhaustion berpengaruh dan signifikan negatif terhadap organizational commitment.

H4: Diduga emotional exhaustion berpengaruh signifikan negatif terhadap organizational commitment.

Mubassyir \& Herachwati (2014) melihat komitmen adalah suatu nilai dari kinerja yang mengindikasikan bahwa seorang karyawan sangat peduli terhadap pekerjaannya. Organizational commitment yang tinggi memiliki hubungan dengan rendahnya tingkat absensi dan kinerja karyawan yang menjadi lebih baik (Khulub \& Hidayati, 2019). Karyawan dengan tingkat organizational commitment yang sangat tinggi, maka ia akan merasa bertanggung jawab penuh terhadap pekerjaannya dan dapat melakukan pekerjaannya tanpa membutuhkan bantuan dari orang lain. Tourigny et. al. (2013), Suharto et. al. (2019), Khan \& Zia-Ud-Din (2013), dan Memari et. al. (2013) membuktikan bahwa variabel organizational commitment memiliki pengaruh positif terhadap kinerja karyawan. Hal ini memiliki makna jika variabel organizational commitment mengalami peningkatan, maka akan terjadi peningkatan dalam kinerja karyawan.

H5: Diduga organizational commitment berpengaruh signifikan positif terhadap kinerja karyawan.

Organizational commitment mempunyai pengaruh yang cukup besar terhadap kinerja. Seorang karyawan yang mempunyai komitmen terhadap organisasinya, maka karyawan tersebut akan menyukai pekerjaannya, ingin lebih terlibat dalam setiap kegiatan organisasi, akan mengupayakan keinginannya untuk tetap bertahan dan setia pada perusahaan, dan akan memiliki rasa loyalitas yang tinggi terhadap perusahaan. Perasaan suka dan nyaman dengan perusahaan inilah yang memiliki dampak pada tingkat kinerja mereka, antara lain karyawan akan berusaha memberikan pelayanan 
Dewi Ayu Lestari \& Budiono. Pengaruh Work Family Conflict dan Emotional Exhaution terhadap Kinerja Perawat Wanita melalui Organizational Commitment pada Rumah Sakit Petrokimia Gresik

dengan sangat baik serta mengupayakan keinginan dan kenyamanan pelanggan (Mubassyir \& Herachwati, 2014).

Mubassyir \& Herachwati (2014) mengungkapkan bahwa secara tidak langsung work family conflict mempunyai pengaruh terhadap kinerja, melalui organizational commitment. Work family conflict mempunyai pengaruh secara langsung terhadap organizational commitment, selanjunya work family conflict yang memengaruhi organizational commitment memiliki pengaruh pula terhadap kinerja. Oleh karena itu, organizational commitment dirasa sanggup menjalankan peran sebagai variabel mediasi (intervening) di dalam penelitian ini. Penilaian tersebut diterima dengan adanya fakta bahwa memang ada pengaruh signifikan antara work-family conflict terhadap organizational commitment dan juga organizational commitment mempunyai pengaruh signifikan terhadap kinerja.

H6: Diduga work family conflict berpengaruh terhadap kinerja karyawan yang dimediasi oleh organizational commitment.

Khulub \& Hidayati (2019) berpendapat bahwa karyawan yang berada pada garis depan yang merasakan emotional exhaustion tidak dapat merasa puas dengan pekerjaannya dan tidak bisa memberikan kinerja yang sesuai dengan keinginan perusahaan. Emotional exhaustion dapat memengaruhi rasa puas ditempat kerja dan juga kinerja pada karyawan front liner. Karena memiliki pengaruh yang kuat itulah yang dapat menimbulkan komitmen karyawan terhadap organisasi tempatnya bekerja.

H7: Diduga emotional exhaustion berpengaruh terhadap kinerja karyawan yang dimediasi oleh organizational commitment.

\section{METODE PENELITIAN}

Penelitian ini dilaksanakan di Rumah Sakit Petrokimia Gresik, yang berlokasi di Jl. Jenderal Ahmad Yani No.69, Gresik. Metode penelitian menggunakan kuantitatif dengan pendekatan uji hipotesis. Metode ini diawali dengan merumuskan hipotesis dan mengkaji beberapa teori, selanjutnya yaitu merancang model analisis, kemudian pengenalan variabel, dan definisi variabel, dilanjutkan dengan melakukan pengumpulan data primer dan sekunder setelah itu menganalisis hasil penelitian yang diperoleh. Metode dalam pengumpulan data melalui penyebaran kuesioner yang dilakukan secara online dengan menggunakan google form melalui link (https://forms.gle/jXY2zUQiANn67fow8). Jenis penelitian kausalitas yaitu untuk melihat ada atau tidaknya dari pengaruh variabel work family conflict, emotional exhaustion, organizational commitment, terhadap kinerja karyawan. Angket yang digunakan bukanlah angket terbuka karena telah disediakan pilihan jawaban sehingga dapat memudahkan para responden dalam menjawab pernyataan. Keseluruhan perawat wanita di Rumah Sakit Petrokimia Gresik yang sudah berkeluarga adalah populasi yang dibutuhkan dalam penelitian ini. Jumlah populasi yang telah memenuhi kriteria adalah 46 orang. Sehingga jumlah dari sampel sebanyak 46 orang perawat wanita yang sudah menikah.

Structural Equation Model (SEM) dengan menggunakan metode analisis Partial Least Square (PLS) adalah teknik analisis yang digunakan untuk pengujian hipotesis dalam penelitian ini. PLS merupakan model persamaan structuralequation modeling yang berbasis komponen atau varian (variance). PLS juga dapat dipergunakan untuk menjelaskan adanya hubungan antar variabel laten, sekaligus juga dapat dipergunakan untuk menganalisis indikator refleksif dan formatif yang tidak dapat dilakukan pada SEM yang berbasis kovarian. Partial Lest Square (PLS) merupakan metode analisis yang powerfull karena tidak berdasarkan banyak asumsi. Data yang diperlukan tidak harus berdistribusi normal multivariate yang maksudnya ialah indikator dengan skala kategori, interval, ordinal, sampai ratio dapat dipergunakan pada model yang sama, dan juga sampel yang dibutuhkan tidak harus dalam jumlah yang besar. 


\section{HASIL DAN PEMBAHASAN}

\section{Convergent Validity}

Apabila nilai korelasi yang didapat lebih dari 0,70 maka semua indikator dapat dianggap valid. Tetapi, jika pada tahap awal penelitian nilai loadings antara 0,50 sampai dengan 0,60 maka dianggap telah cukup (Chin dalam Ghozali, 2014).

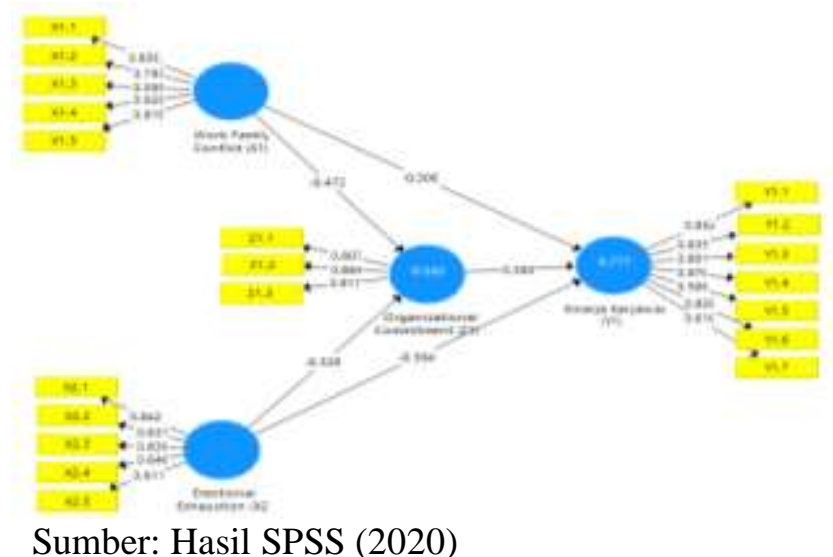

\section{Gambar 1 UJI MEASUREMENT MODEL}

Gambar 1 menjelaskan hasil uji measurement model dan diketahui loadings factor dari empat variabel, outer loadings pada setiap item pernyataan work family conflict (X1) lebih besar angkanya dari 0,50. Ini menjelaskan bahwa indikator work family conflict (X1) valid. Outerloadings dari setiap item pernyataan emotional exhaustion (X2) lebih besar angkanya dari 0,50 ini membuktikan bahwa indikator emotional exhaustion (X2) valid. Outer loadings dari setiap item pernyataan organizational commitment $(\mathrm{Z})$ lebih besar angkanya dari 0,50 . Ini membuktikan bahwa indikator organizational commitment $(\mathrm{Z})$ valid. Outer loadings dari setiap item pernyataan pada variabel kinerja karyawan $(\mathrm{Y})$ lebih besar angkanya dari 0,50. Ini membuktikan bahwa indikator kinerja karyawan (Y) valid.

\section{Discriminant Validity}

Discriminant Validity melihat pada derajat yang tidak sesuai dari beberapa komponen yang semestinya tidak diukur oleh indikator dan beberapa konsep teoritis tentang variabel tersebut.

Tabel 1.

DISCRIMINANT VALIDITY VARIABEL

\begin{tabular}{lcccc}
\hline \multicolumn{1}{c}{ Variabel } & $\begin{array}{c}\text { Emotional } \\
\text { Exhaustion (X2) }\end{array}$ & $\begin{array}{c}\text { Kinerja } \\
\text { Karyawan(Y) }\end{array}$ & $\begin{array}{c}\text { Organizational } \\
\text { Commitment(Z) }\end{array}$ & $\begin{array}{c}\text { Work Family } \\
\text { Conflict (X1) }\end{array}$ \\
\hline Emotional Exhaustion (X2) & 0,721 & & & \\
Kinerja Karyawan (Y1) & $-0,765$ & 0,773 & & \\
Organizational Commitment & $-0,652$ & 0,795 & 0,830 & 0,736 \\
(Z1) & 0,688 & $-0,782$ & $-0,877$ & \\
Work Family Conflict (X1) & & &
\end{tabular}

Sumber: Output Smart PLS 3.0

Tabel 1 menjelaskan bahwa dicriminant validity mempunyai nilai AVE yang lebih besar dari 0.50 . Maka konstruk work family conflict sebesar 0,736 (akar dari 0,542), emotional exhaustion sebesar 0,721 (akar dari 0,519), organizational commitment sebesar 0,830 (akar dari 0,689), dan kinerja karyawan sebesar 0,773 (akar dari 0,598) memenuhi kriteria discriminant validity.

\section{Composite Reliability}

Variabel work family conflict (X1) memiliki nilai composite reliability sebesar 0,852, emotional exhaustion (X2) sebesar 0,841, organizational commitment $(\mathrm{Z})$ sebesar 0,869 dan nilai variabel dari 
Dewi Ayu Lestari \& Budiono. Pengaruh Work Family Conflict dan Emotional Exhaution terhadap Kinerja Perawat Wanita melalui Organizational Commitment pada Rumah Sakit Petrokimia Gresik

kinerja karyawan (Y) adalah sebesar 0,911. Composite reliability dapat dinilai layak jika nilainya di atas 0,70. Mengacu pada penjelasan di atas, dapat diketahui bahwa composite reliability yang ada pada seluruh variabel mempunyai nilai lebih besar dari 0,70. Artinya kriteria composite reliability model variabel sudah terpenuhi atau telah mempuyai reliabilitas yang dapat dikatakan baik.

\section{Cronbach's Alpha}

Variabel work family conflict (X1) menghasilkan nilai cronbach'salpha sebesar 0,792, emotional exhaustion (X2) sebesar 0,760, organizational commitment (Z) sebesar 0,774 dan kinerja karyawan (Y) memiliki nilai sebesar 0,884. Nilai pada cronbach's alpha dapat digunakan apabila lebih besar dari 0,70 mengacu pada penjelasan di atas, dapat dilihat bahwa hasil cronbach 'salpha untuk seluruh konstruk model telah di atas 0,70. Maka model variabel sudah memenuhi kriteria cronbach's alpha atau mempunyai reliabilitas yang dapat dikatakan baik.

\section{Analisis R-Square}

Model pengaruh work family conflict dan emotional exhaustion terhadap organizational commitment menghasilkan nilai dari $r$-square 0,543 dan dapat diinterpretasikan bahwa variabel konstruk organizational commitment dapat dijelaskan oleh variabel work family conflict dan emotional exhaustion sebesar 54,3\% dan variabel yang lain yang tidak termasuk di dalam penelitian ini dapat menjelaskan organizational commitment pada Rumah Sakit Petrokimia Gresik sebesar 45,7\%.

Adapun model pengaruh work family conflict dan emotional exhaustion melalui organizational commitment terhadap kinerja karyawan, dapat dilihat dari nilai $r$-square yang dihasilkan adalah 0,777 dan dapat diartikan bahwa work family conflict dan emotional exhaustion melalui organizational commitment dapat menjelaskan variabel konstruk kinerja karyawan sebesar 77,7\% sedangkan variabel yang lainnya yang tidak termasuk di dalam penelitian ini dapat menjelaskan kinerja karyawan pada Rumah Sakit Petrokimia Gresik sebesar 22,3\%.

\section{Uji Relevansi Prediksi}

Selain dengan melihat nilai $r$-square, model dari PLS juga dapat dilakukan evaluasi dengan cara melihat nilai $q$-square predictive relevance pada model konstruk. Dari hasil perhitungan didapatkan nilai $Q$-squarepredictive relevance yaitu 0,72 dan nilai tersebut memiliki nilai yang lebih besar dari nol. Ini menjelaskan bahwa model tersebut mempunyai predictive relevance yang mampu menjelaskan model sebesar $72 \%$. Hasil perhitungan $q$-square predictive relevance dapat dilihat di rumus (1).

$$
\begin{aligned}
& Q^{2}=1-\left[\left(1-R 1^{2}\right)\left(1-R 2^{2}\right)\right] \\
& Q^{2}=1-\left[\left(1-\left(0,543^{2}\right)\right)\left(1-\left(0,777^{2}\right)\right)\right] \\
& Q^{2}=1-[(1-(0,2948))(1-(0,6037))] \\
& Q^{2}=1-[(0,7052)(0,3963)] \\
& Q^{2}=1-0,2794 \\
& Q^{2}=0,7206 \\
& Q^{2}=0,72
\end{aligned}
$$

\section{Uji Kausalitas}

Gambar 2 menjelaskan hasil uji measurement bootstrapping model untuk mengetahui inner model dari keempat variabel. Penggunaan inner model adalah hubungan antar konstruk dan juga nilai signifikansi yang ada pada tabel 2 path coefficient.

Hasil nilai dari $t$-statistics pengaruh emotional exhaustion (X2) terhadap kinerja karyawan (Y) sebesar $(2,190>1,96)$. Ini menjelaskan bahwa terdapat pengaruh yang signifikan pada variabel emotional exhaustion (X2) terhadap kinerja karyawan (Y) dan nilai koefisien estimasi yang diperoleh sebesar (0,304). Koefisien mempunyai tanda yang negatif artinya jika emotional exhaustion (X2) semakin rendah maka kinerja karyawan (Y) akan semakin meningkat, begitupula sebaliknya. Arti tanda negatif menjelaskan berbanding terbalik. 


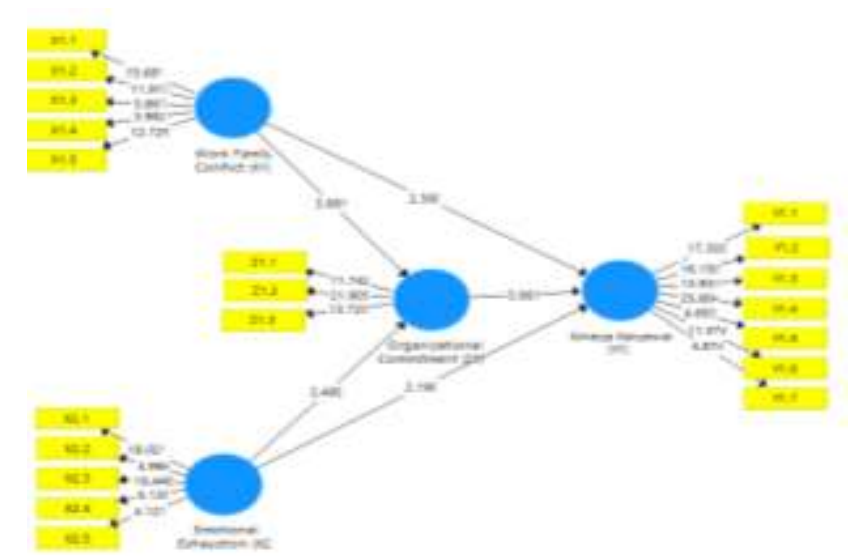

Sumber: Hasil SPSS, 2020

\section{Gambar 2. UJI MEASUREMENT BOOTSTRAPING MODEL}

Hasil nilai dari t-statistics tentang pengaruh emotional exhaustion (X2) terhadap organizational commitment $(\mathrm{Z})$ yaitu $(2,489>1,96)$. Hal ini menjelaskan bahwa terdapat pengaruh yang signifikan pada emotional exhaustion (X2) terhadap organizational commitment (Z) dan hasil koefisien estimasi yaitu $(-0,328)$. Koefisien mempunyai tanda negatif yang bermakna apabila emotional exhaustion (X2) semakin rendah maka organizational commitment (Z) akan semakin meningkat, begitupula sebaliknya. Arti tanda negatif menjelaskan berbanding terbalik.

Hasil nilai dari t-statistics tentang pengaruh organizational commitment $(\mathrm{Z})$ terhadap kinerja karyawan $(\mathrm{Y})$ sebesar $(3,061>1,96)$. Ini menjelaskan bahwa terdapat pengaruh signifikan pada variabel organizational commitment (Z) terhadap kinerja karyawan (Y) dan hasil koefisien estimasinya sebesar $(0,383)$. Koefisien mempunyai tanda positif yang berarti apabila tingkat organizational commitment (Z) makin tinggi maka tingkat kinerja karyawan (Y) juga akan semakin meningkat, begitupula sebaliknya. Arti tanda positif ini menjelaskan berbanding lurus.

Hasil nilai dari t-statistics tentang pengaruh work family conflict (X1) terhadap kinerja karyawan (Y) sebesar $(2,300>1,96)$. Ini menjelaskan bahwa adanya pengaruh signifikan pada variabel work family conflict (X1) terhadap kinerja karyawan (Y) dan hasil koefisien estimasinya yaitu sebesar $(-0,306)$. Koefisien mempunyai tanda negatif yang artinya apabila tingkat work family conflict (X1) semakin rendah maka kinerja karyawan (Y) akan memiliki yang semakin meningkat, begitupula sebaliknya. Arti tanda negatif menjelaskan berbanding terbalik.

Tabel 2.

HASIL PATH COEFFICIENTS

\begin{tabular}{|c|c|c|c|c|}
\hline Hubungan Antar Variabel & Original Sample & T-Statistics & \multicolumn{2}{|c|}{ Keterangan } \\
\hline $\begin{array}{l}\text { Emotional Exhaustion }(\mathrm{X} 2) \rightarrow \text { Kinerja } \\
\text { Karyawan }(\mathrm{Y})\end{array}$ & $-0,304$ & 2,190 & $\begin{array}{c}\geq 1,96 \\
\text { (Signifikan) }\end{array}$ & $\begin{array}{l}\text { Hipotesis } \\
\text { Diterima }\end{array}$ \\
\hline $\begin{array}{l}\text { Emotional Exhaustion }(\mathrm{X} 2) \rightarrow \\
\text { Organizational Commitment }(\mathrm{Z})\end{array}$ & $-0,328$ & 2,489 & $\begin{array}{l}\geq 1,96 \\
\text { (Signifikan) }\end{array}$ & $\begin{array}{l}\text { Hipotesis } \\
\text { Diterima }\end{array}$ \\
\hline $\begin{array}{l}\text { Organizational Commitment }(\mathrm{Z}) \rightarrow \text { Kinerja } \\
\text { Karyawan }(\mathrm{Y})\end{array}$ & 0,383 & 3,061 & $\begin{array}{c}\geq 1,96 \\
\text { (Signifikan) }\end{array}$ & $\begin{array}{l}\text { Hipotesis } \\
\text { Diterima }\end{array}$ \\
\hline $\begin{array}{l}\text { Work Family Conflict }(\mathrm{X} 1) \rightarrow \text { Kinerja } \\
\text { Karyawan }(\mathrm{Y})\end{array}$ & $-0,306$ & 2,300 & $\begin{array}{l}\geq 1,96 \\
\text { (Signifikan) }\end{array}$ & $\begin{array}{r}\text { Hipotesis } \\
\text { Diterima }\end{array}$ \\
\hline $\begin{array}{l}\text { Work Family Conflict }(\mathrm{X} 1) \rightarrow \text { Organizational } \\
\text { Commitment }(\mathrm{Z})\end{array}$ & $-0,472$ & 3,891 & $\begin{array}{c}\geq 1,96 \\
\text { (Signifikan) }\end{array}$ & $\begin{array}{l}\text { Hipotesis } \\
\text { Diterima }\end{array}$ \\
\hline
\end{tabular}

Sumber: Output Smart PLS 3.0

Hasil nilai dari $t$-statistics tentang pengaruh work family conflict (X1) terhadap organizational commitment $(\mathrm{Z})$ sebesar $(3,891>1,96)$. Ini menjelaskan bahwa adanya pengaruh signifikan pada 
Dewi Ayu Lestari \& Budiono. Pengaruh Work Family Conflict dan Emotional Exhaution terhadap Kinerja Perawat Wanita melalui Organizational Commitment pada Rumah Sakit Petrokimia Gresik

variabel work family conflict (X1) terhadap organizational commitment (Z) dan hasil koefisien estimasinya yaitu sebesar $(-0,472)$. Koefisien mempunyai tanda negatif yang berarti ketika tingkat work family conflict (X1) semakin rendah maka organizational commitment (Z) akan memiliki nilai yang semakin tinggi, begitupula sebaliknya. Arti tanda negatif menjelaskan berbanding terbalik.

Dalam penelitian ini diketahui besarnya koefisien pengaruh yang tidak langsung emotional exhaustion (X2) terhadap kinerja karyawan (Y) melalui organizational commitment (Z) yaitu sebesar - 0,126 dan nilai $t$-statistic 1,981 yaitu lebih besar dari 1,96 yang berarti signifikan. Kemudian terdapat besarnya koefisien pengaruh secara tidak langsung oleh work family conflict (X1) ke kinerja karyawan (Y) melalui organizational commitment (Z) yaitu sebesar -0,181dan nilai $t$-statistic 2,202 yaitu lebih besar dari 1,96 yang berarti signifikan. Artinya, pengaruh tidak langsung memiliki pengaruh yang besar dibanding dengan perngaruh secara langsung.

\section{Tabel 3. PENGARUH LANGSUNG DAN TIDAK LANGSUNG}

\begin{tabular}{lccc}
\hline \multicolumn{1}{c}{ Hubungan antar Variabel } & $\begin{array}{c}\text { Original } \\
\text { Sample }\end{array}$ & $\begin{array}{c}\text { T- } \\
\text { Statistics }\end{array}$ & Keterangan \\
\hline $\begin{array}{l}\text { Emotional Exhaustion }(\mathrm{X} 2) \rightarrow \text { Organizational } \\
\text { Commitment }(\mathrm{Z} 1) \rightarrow \text { Kinerja Karyawan(Y1) }\end{array}$ & $-0,126$ & 1,981 & $\begin{array}{c}\text { Hipotesis } \\
\text { Diterima }\end{array}$ \\
Emotional Exhaustion $(\mathrm{X} 2) \rightarrow$ Kinerja Karyawan $(\mathrm{Y} 1)$ & $-0,304$ & 2,190 & $\begin{array}{c}\text { Hipotesis } \\
\text { Diterima }\end{array}$ \\
Work Family Conflict $(\mathrm{X} 1) \rightarrow$ Organizational & $-0,181$ & 2,202 & $\begin{array}{c}\text { Hipotesis } \\
\text { Commitment }(\mathrm{Z} 1) \rightarrow \text { Kinerja Karyawan(Y1) }\end{array}$ \\
Work Family Conflict $(\mathrm{X} 1) \rightarrow$ Kinerja Karyawan $(\mathrm{Y} 1)$ & $-0,306$ & 2,300 & $\begin{array}{c}\text { Hipotesis } \\
\text { Diterima }\end{array}$ \\
\hline
\end{tabular}

Sumber: Output Smart PLS 3.0

\section{Pengaruh Work Family Conflict terhadap Kinerja Karyawan}

Hasil penelitian menunjukkan jika work family conflict memiliki pengaruh terhadap kinerja karyawan sehingga $\mathrm{H} 1$ diterima. Maka dapat diartikan bahwa jika work family conflict semakin tinggi maka kinerjanya akan semakin rendah ataupun dapat bermakna sebaliknya. Work family conflict mampu memengaruhi kinerja karyawan karena semakin rendah tingkat masalah atau konflik yang dialami di rumah dan di lingkungan keluarga maka kinerja perawat di Rumah Sakit Petrokimia Gresik akan mengalami peningkatan.

Berdasarkan hasil wawancara yang talah dilakukan secara tidak terstruktur dengan beberapa perawat wanita yang sudah menikah pada Rumah Sakit Petrokimia Gresik, mereka mengungkapkan bahwa mereka hampir tidak pernah merasakan adanya konflik pekerjaan keluarga (work family conflict) dikarenakan mereka merasa tidak ada tuntutan dari Rumah Sakit bahwa perawat harus selalu lembur dan mereka juga merasa adanya kemudahan dalam menukar hari libur dengan rekan perawat lainnya apabila terdapat keperluan yang mengharuskan perawat untuk libur. Adanya kemudahan untuk perawat yang ingin melakukan izin keluar Rumah Sakit pada jam kerja apabila terdapat hal yang mendesak seperti ketika harus mengambil rapor atau ketika anaknya sakit. Dalam hal mengurus anak dan rumah, mereka juga tidak terlalu khawatir karena sudah ada keluarga lain yang membantu dalam hal ini. Perawat lainnya juga dapat menitipkan anak mereka di TPA (Tempat Penitipan Anak) yang ada di bawah yayasan Petrokimia Gresik. Lokasi TPA juga tidak jauh dari Rumah Sakit Petrokimia Gresik, sehingga apabila jam istirahat, perawat juga dapat menengok anaknya. Perawat tetap dapat fokus dalam pekerjaannya mengurus pasien dan perawat tetap dapat meningkatkan kinerjanya. Peran yang ada di rumah masih dapat dilakukan dengan baik oleh perawat menjadikan keluarga selalu mendukung pekerjaan perawat untuk bekerja sehingga perawat pun dapat meningkatkan kinerja sebagai perawat di Rumah Sakit Petrokimia Gresik.

Studi ini juga memperkuat penelitian yang sudah dilakukan lebih dahulu oleh Septyaningsih \& Palupiningdyah (2017), Sudirno \& Nurvianti (2015), Zain \& Setiawati (2019), Agustina \& Sudibya 
(2018), Mubassyir \& Herachwati (2014), Nabila et. al. (2019), dan Setyawan (2019), bahwa work family conflict memiliki pengaruh signifikan negatif terhadap kinerja karyawan.

\section{Pengaruh Work Family Conflict terhadap Organizational Commitment}

Hasil penelitian menunjukkan jika work family conflict memiliki pengaruh terhadap organizational commitment atau komitmen organisasi, sehingga $\mathrm{H} 2$ diterima. Maka dapat diartikan bahwa ketika tingkat work family conflict semakin tinggi maka organizational commitment akan semakin rendah ataupun dapat bermakna sebaliknya. Work family conflict dapat memengaruhi organizational commitment karena semakin rendah tingkat konflik yang terjadi di rumah dan keluarga maka akan meningkatkan komitmen dalam bekerja di dalam sebuah organisasi yaitu di Rumah Sakit Petrokimia Gresik.

Seperti yang telah dijelaskan sebelumnya mengenai hasil wawancara tingkat work family conflict pada perawat wanita di Rumah Sakit Petrokimia Gresik, yang mengungkapkan bahwa mereka hampir tidak pernah mengalami konflik pekerjaan keluarga. Selain itu, Rumah Sakit Petrokimia Gresik memberikan fleksibilitas para karyawannya salah satunya yaitu bertukar hari libur dengan rekan perawat lainnya, sehingga hal tersebut membuat komitmen perawat yang bekerja di Rumah Sakit Petrokimia Gresik terbentuk. Studi ini juga memperkuat penelitian terdahulu oleh Akintayo (2010), Mubassyir \& Herachwati (2014), Khulub \& Hidayati (2019), dan Jenitta \& Elangkumaran (2013), bahwa work family conflict memiliki pengaruh signifikan negatif terhadap organizational commitment.

\section{Pengaruh Emotional Exhaustion terhadap Kinerja Karyawan}

Hasil penelitian menunjukkan jika emotional exhaustion memiliki pengaruh terhadap kinerja sehingga H3 diterima. Maka dapat diartikan bahwa semakin tinggi tingkat emotional exhaustion maka akan semakin rendah kinerjanya ataupun dapat bermakna sebaliknya. Emotional exhaustion dapat memengaruhi kinerja karyawan karena semakin rendah tingkat stress yang dirasakan perawat maka tingkat kinerja perawat di Rumah Sakit Petrokimia Gresik akan semakin meningkat.

Berdasarkan hasil wawancara yang talah dilakukan secara tidak terstruktur dengan beberapa perawat wanita yang sudah menikah pada Rumah Sakit Petrokimia Gresik, mereka mengungkapkan bahwa mereka hampir tidak pernah merasakan adanya kelelahan emosional (emotional exhaustion) karena perawat selalu merasa enjoy dan nyaman dengan pekerjaan mereka. Jika rasa lelah memang ada, namun perawat dapat mengelola rasa lelah itu sendiri dengan mengobrol atau bercanda sesekali dengan rekan perawat lainnya agar rasa lelah yang dirasakan tidak mengganggu aktivitas bekerja mereka. Peran Rumah Sakit dalam meminimalisir tingkat kelelahan emosional pada perawat wanita yaitu berupa adanya kegiatan family gathering yang diadakan setiap satu tahun sekali, dan melibatkan seluruh karyawan yang ada di Rumah Sakit baik dari karyawan bagian klinis maupun non klinis. Membagi dengan 3 sesi keberangkatan, dan mengambil weekend sebagai hari keberangkatan supaya tidak mengganggu kegiatan operasional perusahaan. Dalam kegiatan family gathering, karyawan juga diperbolehkan untuk mengajak suami/ istri dan anak-anaknya, serta karyawan juga akan mendapatkan uang saku. Selain adanya family gathering, perusahaan juga mengadakan senam pagi dan sarapan bersama setiap hari jum'at untuk karyawan yang ingin melaksanakan senam pagi dengan durasi satu jam. Menurut perawat hal ini dapat menyegarkan kembali kondisi kesehatan badan dan psikologis dari perawat. Hal ini menyatakan bahwa perawat di Rumah Sakit Petrokimia Gresik sama sekali tidak merasakan rasa bosan, lelah ataupun ketidakpuasan selama bekerja di Rumah Sakit Petrokimia Gresik, perawat pun juga tidak merasakan jenuh pada saat menghadapi pasien seharian penuh. Maka dari itu, perawat tetap dapat fokus dalam pekerjaannya mengurus pasien dan perawat tetap dapat meningkatkan kinerjanya.

Hasil penelitian ini mendukung Septyaningsih \& Palupiningdyah (2017), Sudirno \& Nurvianti (2015), dan Tourigny et. al. (2013), bahwa variabel emotional exhaustion memiliki pengaruh signifikan negatif terhadap kinerja karyawan. 
Dewi Ayu Lestari \& Budiono. Pengaruh Work Family Conflict dan Emotional Exhaution terhadap Kinerja Perawat Wanita melalui Organizational Commitment pada Rumah Sakit Petrokimia Gresik

\section{Pengaruh Emotional Exhaustion terhadap Organizational Commitment}

Hasil penelitian menunjukkan jika emotional exhaustion memiliki pengaruh terhadap organizational commitment sehingga $\mathrm{H} 4$ diterima. Maka ketika tingkat emotional exhaustion semakin tinggi, tingkat organizational commitment akan semakin rendah ataupun dapat bermakna sebaliknya. Emotional exhaustion dapat memengaruhi organizational commitment karena semakin rendah tingkat stress perawat maka akan meningkatkan komitmen dalam bekerja di dalam sebuah organisasi yaitu di Rumah Sakit Petrokimia Gresik.

Seperti yang telah dijelaskan sebelumnya mengenai hasil wawancara tingkat emotional exhaustion pada perawat wanita di Rumah Sakit Petrokimia Gresik, yang mengungkapkan bahwa mereka hampir tidak pernah mengalami kelelahan emosional. Selain itu, Rumah Sakit Petrokimia Gresik selalu mengadakan kegiatan-kegiatan yang dapat meningkatkan mood karyawan. Kelelahan emosional yang dirasakan perawat masih dapat dikelola dengan baik oleh perawat menjadikan perawat tidak merasa beban dalam pekerjaannya, lelah, bosan, dan merasa ingin meninggalkan perusahaan dan dapat berkomitmen untuk bekerja sebagai perawat di Rumah Sakit Petrokimia Gresik.

Hasil penelitian ini sependapat dengan Herlina \& Rachmawati (2014), Khulub \& Hidayati (2019), Santika \& Sudibia (2017), Churiyah (2017), Ahmed (2015), Tourigny et. al. (2013), Rehman et. al. (2012) dan Zhen (2013) menemukan adanya pengaruh negatif dari emotional exhaustion terhadap organizational commitment.

\section{Pengaruh Organizational Commitment terhadap Kinerja Karyawan}

Hasil penelitian menunjukkan jika organizational commitment memiliki pengaruh terhadap kinerja karyawan. Ketika tingkat organizational commitment semakin tinggi maka tingkat kinerja perawat bekerja di Rumah Sakit Petrokimia Gresik akan semakin tinggi pula. Organizational commitment mampu menjadi faktor kontekstual untuk meningkatkan kerja karywan dengan adanya niatan perawat yang terus berkomitmen dari segi ingin terus melanjutkan kerja di Rumah Sakit karena organisasi memiliki arti yang besar bagi perawat, lalu berkomitmen karena perawat membutuhkan pekerjaan yang sekarang sedang dilakukan.

Berdasarkan hasil wawancara yang talah dilakukan secara tidak terstruktur dengan beberapa perawat wanita yang sudah menikah pada Rumah Sakit Petrokimia Gresik, mereka mengungkapkan bahwa mereka merasa nyaman bekerja dengan organisasi, beberapa hal yang dapat membuat perawat nyaman dengan organisasi adalah rekan kerja yang hangat dan peran atasan yang dapat mendukung mereka, membuat mereka enggan untuk meninggalkan organisasi. Disamping itu sulitnya mencari pekerjaan pada saat ini juga menjadi salah satu faktor yang mendorong mereka untuk tetap mempertahankan pekerjaannya dan berusaha untuk tidak meninggalkan organisasi saat ini. Dapat diketahui pula dari nilai yang paling kecil yaitu pada item indikator komitmen afektif. Hal ini menyatakan bahwa perawat di Rumah Sakit Petrokimia Gresik merasa bahwa organisasi atau perusahaan telah layak untuk memperoleh kesetiaan dari karyawan dan karyawan bahagia menghabiskan sisa karirnya bersama perusahaan. Perasaan seperti ini akan dapat meningkatkan kinerja perawat.

Hasil penelitian ini memiliki konsistensi untuk memperkuat justifkasi penelitian terdahulu dari Zain \& Setiawati (2019), Mubassyir \& Herachwati (2014), Tourigny et. al. (2013), Khan \& Zia-Ud-Din (2013), Suharto et. al. (2019), dan Memari et. al. (2013), yang menjelaskan bahwa variabel organizational commitment berpengaruh signifikan positif terhadap kinerja karyawan.

\section{Pengaruh Work Family Conflict terhadap Kinerja Karyawan dengan Organizational Commitment sebagai variabel Intervening}

Hasil penelitian menunjukkan jika work family conflict memiliki pengaruh terhadap kinerja karyawan melalui organizational commitment. Maka dapat diartikan bahwa adanya pengaruh antara work family conflict dengan kinerja perawat bekerja di Rumah Sakit Petrokimia Gresik memiliki pengaruh tidak 
langsung yaitu pengaruh negatif yang dapat dijelaskan bahwa jika work family conflict mempunyai nilai rendah melalui variabel mediasi maka tingkat kinerja perawat akan mengalami peningkatan.

Hasil penelitian tersebut mendukung penelitian dari Mubasyir \& Herachwati (2014), bahwa workfamily conflict mempunyai pengaruh secara tidak langsung terhadap kinerja karyawan, namun harus melalui organizational commitment terlebih dahulu. Work family conflict mempunyai pengaruh secara langsung terhadap organizational commitment, di mana organizational commitment yang dipengaruhi oleh work family conflict ini dapat memberikan pengaruh terhadap kinerja.

\section{Pengaruh Emotional Exhaustion terhadap Kinerja Karyawan dengan Organizational Commitment sebagai Variabel Intervening}

Hasil penelitian menunjukkan jika emotional exhaustion memiliki pengaruh terhadap kinerja karyawan melalui organizational commitment, $\mathrm{H} 7$ diterima. Maka dapat diartikan bahwa adanya pengaruh antara emotional exhaustion terhadap kinerja karyawan perawat wanita melalui komitmennya bekerja di Rumah Sakit Petrokimia Gresik memiliki pengaruh tidak langsung yaitu pengaruh negatif yang dapat diartikan bahwa jika emotional exhaustion memiliki nilai rendah melalui variabel mediasi maka tingkat kinerja perawat akan semakin meningkat.

Studi ini juga memperkuat penelitian terdahulu oleh Khulub \& Hidayati (2019) yang mengatakan jika tenaga kerja dalam bidang pelayanan yang mengalami emotional exhaustion tidak dapat merasakan adanya kepuasan dalam pekerjaannya dan tidak akan dapat memenuhi kinerja yang diinginkan.

\section{KESIMPULAN}

Work family conflict dan emotional exhaustion terhadap kinerja karyawan bersifat fluktuatif, artinya work family conflict dan emotional exhaustion dapat dikategorikan rendah maupun dikategorikan tinggi tergantung dari faktor-faktor yang mempengaruhinya. Rendahnya work family conflict dan emotional exhaustion serta tingginya tingkat organizational commitment dapat dijelaskan oleh beberapa faktor yaitu peran perusahaan yang selalu mendukung dan mengfasilitasi karyawan juga karyawan merasa nyaman bekerja dengan organisasi, rekan kerja yang hangat dan peran atasan yang mendukung.

Bagi perusahaan, diharapkan keadaan perawat yang tidak mengalami work family conflict dan emotional exhaustion maupun organizational commitment dan kinerjanya tinggi seperti apa yang terjadi ketika penelitian dilakukan sebaiknya bisa dipertahankan, dengan cara tetap memelihara kekompakan pada tim serta menciptakan iklim kerja yang kondusif supaya tugas dan pekerjaan karyawan dapat berjalan dengan lancar, hubungan antar rekan kerja juga hubungan dengan pimpinan dapat tetap baik sehingga kinerja perawat serta komitmennya dapat mengalami peningkatan. Cara lain yang dapat dilakukan adalah dengan memberikan extra fooding atau asupan makanan bergizi tambahan untuk membantu menjaga stamina karyawan.

Penelitian ini hanya membahas penerapan work family conflict, emotional exhaustion, organizational commitment dan kinerja karyawan pada satu objek perusahaan yang bergerak di bidang kesehatan di Gresik. Penelitian selanjutnya supaya dapat menambahkan beberapa objek penelitian atau perusahaan sehingga nantinya gambaran yang didapat lebih komprehensif mengenai penerapan work family conflict, emotional exhaustion, organizational commitment dan kinerja karyawan pada perusahaan di bidang lainnya. Penelitian ini juga dapat dikembangkan dengan cara menambah beberapa variabel lainnya yang tidak tercantum di dalam model penelitian seperti variabel stres kerja, kepuasan kerja, dan turnover.

\section{DAFTAR PUSTAKA}

Agustina, R., \& Sudibya, I. G. A. (2018). Pengaruh Work Family Conflict Terhadap Stres Kerja dan Kinerja Wanita Perawat di Rumah Sakit Umum Daerah Praya Lombok. E-Jurnal Ekonomi Dan 
Dewi Ayu Lestari \& Budiono. Pengaruh Work Family Conflict dan Emotional Exhaution terhadap Kinerja Perawat Wanita melalui Organizational Commitment pada Rumah Sakit Petrokimia Gresik

Bisnis Universitas Udayana, 3, 775-808. https://doi.org/10.24843/eeb.2018.v07.i03.p06

Ahmed, N. O. A. (2015). Impact of Emotional Exhaustions on Turnover Intentions: A Mediating Role of Organizational Commitment in Higher Education Institutes of Saudi Arabia. International Journal of Economics and Business Administration, III(3), 13-26. https://doi.org/10.35808/ijeba/76

Akintayo, D. I. (2010). Work Family Role Conflict and Organizational Commitment among Industrial Workers in Nigeria. Journal of Psychology and Counseling, 2(1), 1-8. http://www.academicjournals.org/JPC

Askolani, A., \& Maulid, D. L. (2019). The Effect of Job Satisfaction and Organizational Commitment to Performance of Employees Dinas Pendidikan Kota Bandung. 1st International Conference on Economics, Business, Entrepreneurship, and Finance, 65(Icebef 2018), 264-269. https://doi.org/10.2991/icebef-18.2019.60

Churiyah, M. (2017). Pengaruh Kelelahan Emosional Terhadap Kepuasan Kerja Dan Komitmen Organisasional. E-Jurnal Manajemen Universitas Udayana, 6(2), 255170.

Herlina, \& Rachmawati, R. (2014). Pengaruh Emotional Labor dan Emotional Exhaustion terhadap Kepuasan Kerja dan Komitmen Organisasional Afektif pada Flight Attendant Studi Kasus pada Perusahaan Garuda Indonesia Tbk . Abstrak The Effect of Emotional Labor and Emotion Exhaustion toward Job. Management, Faculty of Economic, University of Indonesia, Depok, Indonesia., 1-20.

Jenitta, J. N., \& Elangkumaran, P. (2013). An Impact of Work Family Conflict on Organizational Commitment: A Study of Staff Members at People's Bank in Trincomalee District. International Journal Of Research In Commerce \& Management, 4(11), 0976-2183.

Khan, M. R., \& Zia-Ud-Din. (2013). The impact of Organizational Commitment on Employees Job Performance. "A study of Oil and Gas sector of Pakistan." International Islamic University, Islamabad, 3(1984), 30.

Khulub, T., \& Hidayati, L. A. (2019). Peran Ganda dan Kelelahan Emosional terhadap Komitmen Organisasi dengan Kepuasan Kerja sebagai Variabel Mediasi pada Karyawati CV. Nika Indonesia. Jurnal Maksipreneur, 2(1), 1-19.

Memari, N., Mahdieh, O., \& Marnani, A. B. (2013). The Impact of Organizational Commitment on Employees Job Performance. "A study of Meli Bank." Interdisciplinary Journal of Contemporary Research in Business, 5(5), 164-171.

Mubassyir, A. H., \& Herachwati, N. (2014). Pengaruh Work-Family Conflict terhadap Kinerja Perawat Wanita dengan Variabel Intervening Komitmen Organisasional di RSUD Bhakti Dharma Husada Surabaya. Manajemen Teori Dan Terapan, 7(3), 143-162.

Murty, W. A., \& Hudiwinarsih, G. (2012). Pengaruh Kompensasi, Motivasi dan Komitmen Organisasional terhadap Kinerja Karyawan bagian Akuntansi (Studi Kasus pada Perusahaan Manufaktur di Surabaya). The Indonesian Accounting Review, 2(02), 215. https://doi.org/10.14414/tiar.v2i02.97

Nabila, A., Utami, H. N., \& Aini, E. K. (2019). Pengaruh Work Family Conflict Terhadap Kinerja Karyawan Melalui Stres Kerja (Studi Pada Karyawan divisi Operational dan Servis pada PT. Bank BRI Syariah, Tbk. Jurnal Administrasi Bisnis, 73(2), 57-67.

Rehman, O., Karim, F., Rafiq, M., \& Mansoor, A. (2012). The Mediating Role of Organizational 
Commitment between Emotional Exhaustion and Turnover Intention among Customer Service Representatives in Pakistan. African Journal of Business Management, 6(34), 9607-9616. https://doi.org/10.5897/ajbm11.2411

Santika, P. B., \& Sudibia, G. A. (2017). Pengaruh Kelelahan Emosional terhadap Kepuasan Kerja dan Komitmen Organisasi. E-Jurnal Manajemen Unud, 6(2), 634-662.

Septyaningsih, R., \& Palupiningdyah. (2017). Pengaruh Beban Kerja Berlebih dan Konflik Pekerjaan Keluarga terhadap Kinerja melalui Kelelahan Emosional. Management Analysis Journal, 6(4), 461-472. https://doi.org/10.15294/maj.v6i4.18341

Setyawan, D. (2019). Pengaruh Work Family Conflict, Stres Kerja dan Kepuasan Kerja terhadap Kinerja Karyawan (Studi pada Karyawan Wanita PT. Putra Tunas Subur Pacitan). Jurnal Manajemen Universitas Muhammadiyah Yogyakarta, 13, 27.

Sihaloho, R. D., \& Handayani, R. (2018). Pengaruh work-to-family conflict terhadap komitmen the effect of work-to-family conflict on Organizational Commitments in Indonesia Port I ( Persero ) Medan. Jurnal Konsep Bisnis Dan Manajemen, 5(1), 25-38.

Sudirno, H. D., \& Nurvianti, D. V. (2015). Konflik Peran dan Kelelahan Emosional Pengaruhnya terhadap Kinerja Dosen pada Universitas Majalengka. Jurnal Ilmiah Manajemen Dan Akuntansi, 2(1).

Suharto, Suyanto, \& Hendri, N. (2019). The Impact of Organizational Commitment on Job Performance. International Journal of Economics and Business Administration, 7(2), 189-206. https://doi.org/10.35808/ijeba/227

Tourigny, L., Baba, V. V., Han, J., \& Wang, X. (2013). Emotional Exhaustion and Job Performance: The Mediating Role of Organizational Commitment. International Journal of Human Resource Management, 24(3), 514-532. https://doi.org/10.1080/09585192.2012.694109

Zain, A. N. D., \& Setiawati, T. (2019). Influence of Work Family Conflict and Job Satisfaction on Medical Employee Performance through Organizational Commitment. Review of Integrative Business and Economics Research, 8(1), 1-19. https://search.proquest.com/docview/2088048618?accountid=17242

Zhen, Y. A. (2013). The Impact of Communication Satisfaction and Emotional Exhaustion on Organizational Commitment. Master of Business Administration, no 3(April), 95. 